\title{
Utilização de jardins sépticos no tratamento de esgoto doméstico com vala de infiltração saturada
}

A utilização de plantas para tratamento de esgotos é uma alternativa de baixo custo, eficiente e pouca manutenção. Apesar de não ser uma técnica nova, a utilização de sistemas que imitam processos naturais, uma opção aos sistemas convencionais, tem se mostrado eficiente, promovendo um tratamento simultaneamente aeróbio e anaeróbio, retirando sólidos suspensos e microrganismos patogênicos e, consequentemente, diminuindo a carga orgânica. Outros benefícios incluem a redução de odor, a estética da vegetação e o apelo ecológico, fazendo com que as comunidades que recebem este tipo de sistema o aceitem com maior facilidade. Desta forma, o trabalho tem como objetivo propor o uso de plantas, como tratamento auxiliar de esgoto doméstico para um sistema fossa séptica com vala de infiltração. O sistema estudado, fossa séptica e vala de infiltração, encontra-se em funcionamento desde a década de 1980 , dado o tempo de funcionamento e um número maior de usuários, para o qual foi projetado encontra-se saturado. Com a utilização de plantas ornamentais para o tratamento haverá a criação de um jardim de contemplação, suprindo assim uma carência nesta comunidade. Isto posto, foram sugeridos alguns tipos de plantas ornamentais, as mais utilizadas no Nordeste do Brasil, que foram avaliadas para tratamento do efluente e aspecto estético. A metodologia baseou-se em estudo exploratório sobre o tema, a fim de definir as diretrizes do projeto do SAC (sistema de alagados construídos), como dimensionamento, camadas e espécies adaptadas. Destaca-se que, segundo a literatura, as espécies Helicônia e Canna, são as mais adequadas ao uso em sistemas saturados como o estudado, devido à alta taxa de evapotranspiração que estas possuem em climas tropicais e um estudo piloto deverá ser realizado a fim de avaliar as outras espécies ornamentais comuns e adaptadas no Nordeste brasileiro.

Palavras-chave: Sistemas de Alagados Construídos; Água Residuária; Vala de Infiltração; Plantas Ornamentais; Evapotranspiração.

\section{Use of septic gardens in the treatment of domestic sewage with saturated infiltration ditch}

\begin{abstract}
The use of sewage treatment plants is a low cost, efficient and low maintenance alternative. Although not a new technique, the use of systems that mimic natural processes, an option to conventional systems, has been shown to be efficient, promoting both aerobic and anaerobic treatment, removing suspended solids and pathogenic microorganisms and, consequently, reducing the organic load. . Other benefits include odor reduction, vegetation aesthetics and ecological appeal, making communities receiving this type of system more readily accept it. Thus, the work aims to propose the use of plants as auxiliary treatment of domestic sewage for a septic tank system with infiltration ditch. The studied system, septic tank and infiltration ditch, has been in operation since the 1980 s, given the operating time and a larger number of users for which it was designed is saturated. Using ornamental plants for the treatment will create a garden of contemplation, thus supplying a need in this community. Thus, some types of ornamental plants, the most used in the Northeast of Brazil, which were evaluated for effluent treatment and aesthetic appearance were suggested. The methodology was based on an exploratory study on the subject, in order to define the project guidelines of the SAC (constructed wetland system), such as sizing, layers and adapted species. It is noteworthy that, according to the literature, Heliconia and Canna species are the most suitable for use in saturated systems such as the studied one, due to the high rate of evapotranspiration that they have in tropical climates and a pilot study should be performed to to evaluate the other common and adapted ornamental species in northeastern Brazil.
\end{abstract}

Keywords: Constructed flooded systems; Wastewater; Infiltration Ditch; Ornamental Plants; Evapotranspiration.

Topic: Engenharia Ambiental

Reviewed anonymously in the process of blind peer.
Received: 02/10/2019

Approved: 26/11/2019
Ernani Gomes da Fonseca Júnior (iD)

Instituto de Tecnologia de Pernambuco, Brasil

http://lattes.cnpq.br/5484847920095715

http://orcid.org/0000-0003-0662-6381

ernanijunior@gmail.com

Helena Paula de Barros Silva

Universidade de Pernambuco, Brasil

http://lattes.cnpq.br/8032029104613904

helena.silva@upe.br

Ronaldo Faustino da Silva (id)

Instituto Federal de Pernambuco, Brasil

http://lattes.cnpq.br/7265569987870357

http://orcid.org/0000-0001-8097-9420

ronaldofaus@gmail.com
Daniele de Castro Pessoa de Melo (D)

Universidade Federal de Pernambuco, Brasil

http://lattes.cnpq.br/4010783198064867

http://orcid.org/0000-0003-4058-092X

daniele.castro@itep.b
Referencing this:

FONSECA JÚNIOR, E. G.; SILVA, H. P. B.; SILVA, R. F.; MELO, D. C. P.. Utilização de jardins sépticos no tratamento de esgoto doméstico com vala de infiltração saturada. Revista Ibero Americana de Ciências Ambientais, v.10, n.6, p.231-240, 2019. DOI:

http://doi.org/10.6008/CBPC2179-6858.2019.006.0020

DOI: 10.6008/CBPC2179-6858.2019.006.0020 


\section{INTRODUÇÃO}

No Brasil, a história do saneamento se inicia com o processo de surgimento e formação das cidades, mas a implantação de uma infraestrutura mínima se deu apenas com a chegada da Família Real no Rio de Janeiro. Assim como em outras partes do mundo, houve um crescimento das cidades e grande fluxo migratório para estas no século XIX, o que impulsionou o agravamento dos problemas de saneamento básico, como as epidemias, por exemplo (LACERDA JUNIOR, 2010).

Com o passar do tempo, cada vez mais o saneamento básico e a descontaminação das águas começaram a ser vistos como elementos vitais para o desenvolvimento econômico. Os processos e os sistemas de tratamento são variados, tais como: químicos, físicos, biológicos ou combinados, que possibilitam a purificação dos esgotos. No entanto a água como recurso hídrico finito e vulnerável, só vem sendo vista desta forma a pouco tempo, devido ao crescimento desordenado da população, principalmente as urbanas. Desta forma, fez-se necessário o estudo de técnicas de tratamento de água e esgotos, adequadas a esta realidade (CRUZ, 2010).

Adequando-se a realidade de um crescimento desordenado da população e a falta de planejamento urbano, principalmente nas áreas urbanas, os sistemas convencionais de tratamento de esgotos chegam com uma proposta de procedimento para que os efluentes gerados possam ser tratados e estes trazem consigo um dos conceitos mais conhecidos as Estações de Tratamento de Esgotos, conhecidas como ETEs, que tratam e dispõem do efluente em corpos de água e a utilização de fossas sépticas e sumidouro, para pequenas comunidades, com disposição profunda do efluente no solo (GALBIATI, 2009).

A utilização de plantas no tratamento de esgotos, como vislumbrado em Wetlands naturais, é uma tecnologia emergente, eficiente, estética e de baixos custos energéticos e operacionais, com flexibilidade de operação, e que atualmente tem se revelado como uma boa alternativa aos sistemas convencionais (ALMEIDA et al., 2005) e tem sido utilizada como alternativa para tratamento de esgoto doméstico de pequenas comunidades, conforme exposto por Shelef (2013) "o esgoto tratado por sistemas alagados construídos, tem ganho popularidade nas últimas 4 décadas como alternativa ao tratamento convencional". Estes sistemas utilizam plantas que simulam as características das macrófitas das wetlands naturais, onde suas raízes atuam como filtros, removendo contaminantes, e degradando microbiologicamente a matéria orgânica através de interações bioquímicas.

Ainda de acordo com Brix (1994), os mecanismos de degradação da matéria orgânica são realizados "por biofilmes de microrganismos formados no meio poroso e na rizosfera". Almeida et al. (2007) afirma que a vegetação desempenha um papel fundamental no tratamento de esgotos com plantas, pela transferência de oxigênio através das raízes e rizomas, ao fundo dos leitos de tratamento, tornando o ambiente propício ao desenvolvimento de microrganismos que atuam no tratamento biológico (TCHOBANOGLOUS, 1991). Portanto, os sistemas alagados construídos ou wetland construídas, envolvem um sistema de construção ecológica onde três componentes importantes colaboram: i) meio filtrante poroso; ii) microrganismos e iii) vegetação (SANDOVAL, 2019). 
Normalmente, o sistema com plantas é utilizado como tratamento secundário (TCHOBANOGLOUS, 1991; SIEVERS, 1993); porém o mesmo pode ser utilizado no tratamento primário (SOLANO et al., 2004), desde que o esgoto bruto esteja livre de material grosseiro. A escolha das plantas vai depender do objetivo do sistema, ou seja, máxima eficiência de tratamento, interesse paisagístico ou produção de biomassa, sendo que um necessariamente não exclui o outro. Para definir-se o tipo de wetland construído ou SACs (sistema de alagado construído) é necessário que se avalie o efluente a ser tratado ajustando o sistema mais apropriado as necessidades do projeto.

Logo, existindo a necessidade de adequação do projeto, é importante que se relate os sistemas mais utilizados no tratamento de efluente. Segundo Pereira (2013) os sistemas de wetlands construídos mais utilizados são os que, ou utilizam aplicação direta do efluente no solo com baixa ou alta taxa de infiltração ou escoamento superficial, contudo, este é considerado por alguns órgãos ambientais como restrito pela possível contaminação do solo e do lençol freático, pela falta de impermeabilização e controle; ou os sistemas de reatores construídos em áreas delimitadas e impermeabilizadas, especialmente projetadas para o tratamento de águas residuais e receberem a carga de poluentes.

Definindo-se então o tipo de Jardim séptico ou SACs, a vegetação a ser utilizada neste trabalho foi avaliado correspondendo a melhor tratativa e resposta ao proposto no projeto. Trabalhos mais recentes vêm evidenciando o uso de plantas ornamentais em SACs, como a Helicônia (Heliconia psittacorum) (KONNERUP et al., 2009), o copo-de-leite (Zantedeschia aethiopica), o antúrio (Anthurium andreanum), por exemplo. Sandoval (2019) indica as plantas ornamentais mais utilizadas em alguns países para remoção de poluentes, no caso do Brasil para tratamento de esgoto doméstico é citado o caso da 'Heliconia psittacorum, com uma remoção de DQO da ordem de 95\% e SST $88 \%$, já a canna sp, segundo o mesmo autor, a remoção de DQO os valores ficam entre 48 e $90 \%$, enquanto SST é de $34 \%$.

Zanella (2008) aponta que o uso dessas plantas proporciona um efeito paisagístico, diminuindo os índices rejeição do sistema pela população e, "com a introdução de espécies de interesse comercial, há possibilidade de geração de trabalho e renda para a população circunvizinha". Ainda de acordo com Belmont et al. (2003), o cultivo de plantas ornamentais em sistema alagados pode fornecer um benefício econômico, incentivando pequenas comunidades a manter um sistema de tratamento de esgoto.

Outro aspecto das wetlands construída deve ser levada em consideração. Trata-se da evapotranspiração (ET) que será aumentada ou não a depender do crescimento das plantas ornamentais a serem utilizadas. Desta forma, onde o suprimento de água é raramente limitado, conforme Mitsch et al. (2007 citado por HEADLEY, 2012) "a taxa de ET é proporcional à diferença entre a pressão de vapor na superfície da água ou das folhas e a pressão de vapor no ar subjacente". Em consequência, a evapotranspiração, como visto, é afetada por fatores como a radiação solar, temperatura da superfície, umidade e velocidade do vento.

Diante do exposto o objetivo do trabalho foi propor um tratamento de águas residuárias proveniente de um sistema de fossa séptica e vala de infiltração, onde a vala de infiltração, devido o tempo de uso, 20 anos e tendo o afluente advindo de uma fossa que não passa por limpezas regulares está saturada, e para 
recompor a eficiência foi projetado um sistema construído alagado, jardim séptico, com plantas ornamentais utilizadas no paisagismo nacional seguindo o conceito Wetlands naturais.

\section{METODOLOGIA}

\section{Caracterização da área de estudo}

A pesquisa foi desenvolvida no campus Recife do Instituto Federal de Educação, Ciência e Tecnologia de Pernambuco - IFPE localizado na Av. Luiz Freire, 500 - Curado, na cidade de Recife, Estado de Pernambuco, Figura 1, possuindo uma área de 120. 559,92 m². O clima na região deste estudo, a cidade do Recife, tem um clima tropical úmido, tipo As' segundo classificação de Köppe-Geiger, com temperaturas do ar variando de um máximo diário de $33^{\circ} \mathrm{C}$, a uma mínima diária de $20^{\circ} \mathrm{C}$ e a umidade relativa do ar mínima absoluta é de $41^{\circ} \mathrm{C}$ e média de chuva anual de $1476 \mathrm{~mm}$, dados de 2018, sendo esses valores influenciados pela de latitude de $08^{\circ} 03$ ' 31,68320 " S e longitude $34^{\circ} 57^{\prime}$ 01,38486 "W, conforme dados do IBGE (2018).

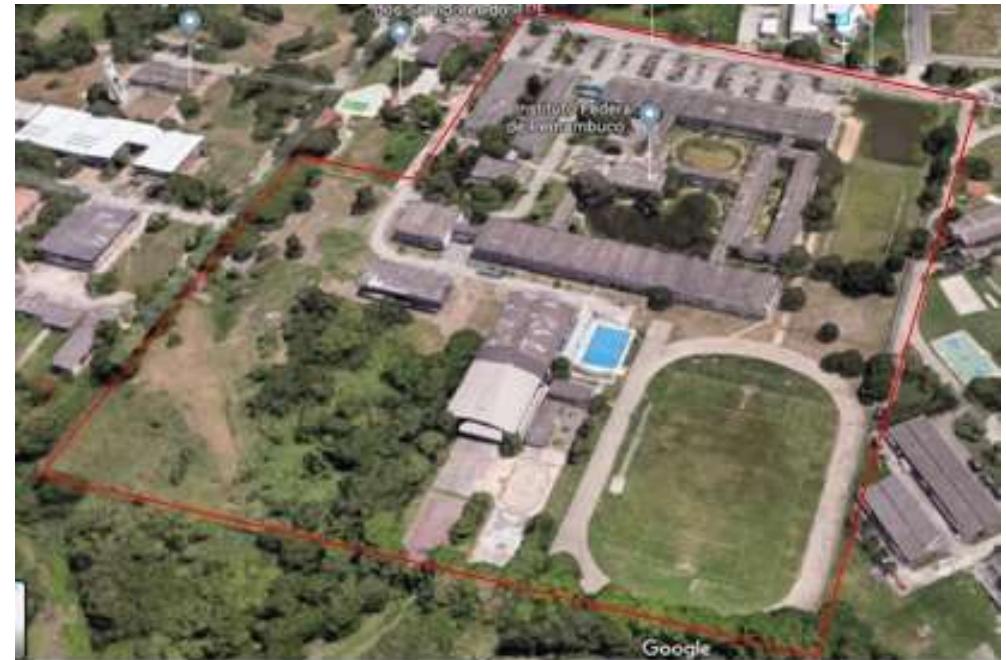

Figura 1: Instituto Federal de Educação, Ciência e Tecnologia de Pernambuco.

\section{Descrição do sistema de tratamento de esgotos implantado}

O sistema de tratamento de esgoto doméstico (Figura 2) foi projetado e construído na década de 1980 para atender um público de 4 mil pessoas, sendo composto por duas fossas sépticas de $90 \mathrm{~m}^{3}, 36$ valas de infiltração com 30 metros cada, totalizando 1.080 metros linear de vala e 15 valas de filtração de 30 metros ocupando uma área de $2.300 \mathrm{~m}^{2}$, uma vez que a área dentro do Recife possui um lençol freático muito próximo à superfície. Para a construção das valas de infiltração na época por ser considerada uma área de permeabilidade baixa, houve a substituição do solo por areia selecionada vindo do litoral de Olinda, Pernambuco. 


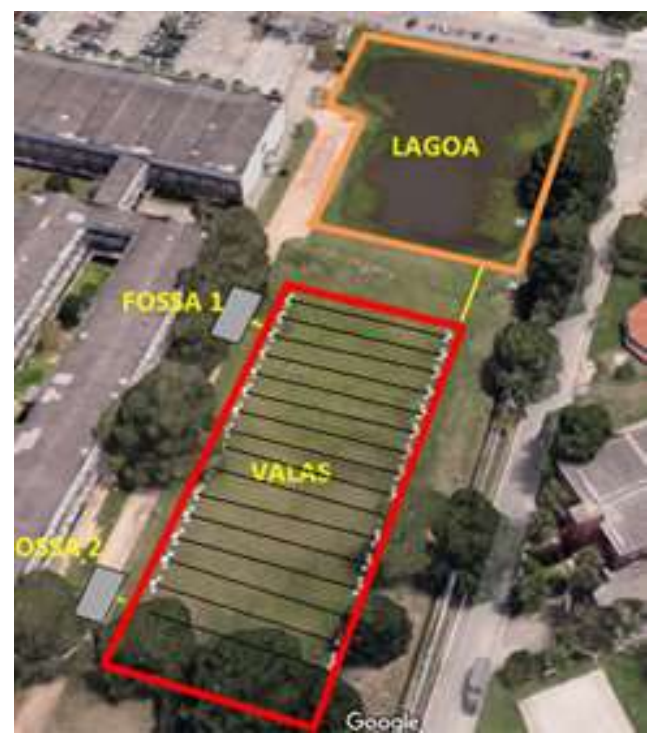

Figura 2: Sistema de Tratamento de água residuária do IFPE- Campus Recife.

\section{Verificação da Saturação da Valas de Infiltração}

Para identificação da saturação das valas de infiltração, foram realizadas sondagem do solo na área através da perfuração de 5 furos de $50 \mathrm{~cm}$ de diâmetro por $10 \mathrm{~cm}$ de profundidade, sendo 4 furos dentro da área das valas, e um furo fora da área, conforme está demonstrado na Figura 3.

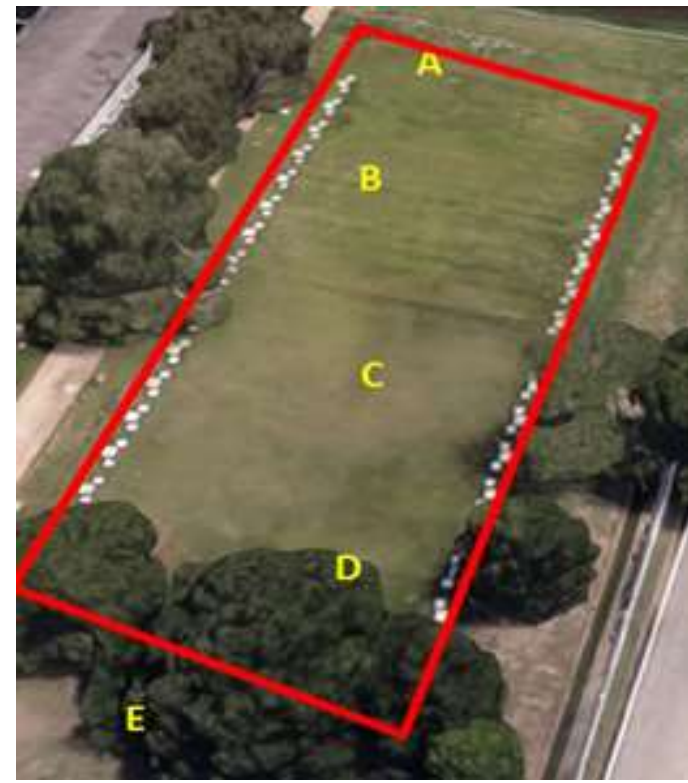

Figura 3: Localização dos pontos de sondagem.

\section{Dimensionamento do sistema da década de 1980 e o projetado}

O dimensionamento do sistema foi realizado conforme as especificações da Agência Estadual de Meio Ambiente, o órgão responsável pela fiscalização no estado de Pernambuco. As especificações da CPRH seguem as normas da ABNT, NBR $7220^{1}$. NBR $13969^{2}$, e NBR $12209^{3}$, que tratam de tanques sépticos, unidades de tratamento complementar e disposição final dos efluentes líquidos, projeto, construção e

\footnotetext{
${ }^{1}$ Construção e instalação de fossas sépticas e disposição dos efluentes finais.

2 Tanques sépticos - unidades de tratamento complementar e disposição final dos efluentes líquidos -projeto, construção e operação.

${ }^{3}$ Elaboração de projetos hidráulico-sanitários de sistema de tratamento de esgotos sanitários
} 
operação, e que tem como objetivo "adotar critérios e condições técnicas para projeto e execução de sistemas básicos para tratamento e destinação final de esgoto sanitário nas áreas desprovidas de coletor público". Na determinação da área necessária para recebimento dos despejos dos efluentes nas valas de infiltração utilizou-se a expressão:

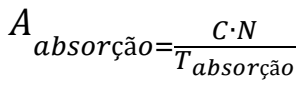

Onde: $\mathrm{A}_{\text {absorção }}=$ área de absorção necessária para percolação do efluente através de valas de infiltração; $\mathrm{N}=$ número de contribuintes. $C=$ contribuição per capita. $\mathrm{T}_{\text {absorção }}$ taxa de absorção (percolação) do solo.

Os valores utilizados para contribuição per capita de esgotos, C (Litro/dia), foram de 50 L/dia e estimado o coeficiente de infiltração ( $\left(\mathrm{L} / \mathrm{m}^{2} \mathrm{xdia}\right)$ maior do que $90 \%$ e a absorção relativa é especificada como rápida faixa 5, "de areia bem selecionada e limpa, variando a areia grossa com cascalhos" (ABNT, 1993).

\section{Estimativa da Taxa de Evapotranspiração}

A estimativa da evapotranspiração de referência (ETo) para o Instituto Federal Campus- Recife/PE, foi obtida com base nos dados de temperatura média, máxima e mínima diárias, umidade relativa do ar média, máxima e mínima diárias, disponibilizados pela Agência Pernambucana de Águas e Clima-APAC. O método adotado foi o proposto por Hargreaves et al., por ser o mais adequado para estimativa da evapotranspiração potencial na Região Nordeste. A equação para determinação da $E t_{0}$, dada em mm.d ${ }^{-1}$, foi: $E t_{0}=0,0023 Q_{0}(T$ $\max -T \min )^{0,5}(T+17,8)$, Onde:

$E t_{0}=$ Evapotranspiração de referência, em $m \cdot{ }^{-1}$; $\mathrm{Q}_{0}=$ radiação extraterrestre, convertida em $\mathrm{mm} \cdot \mathrm{d}^{-1} \mathrm{e}$ cujos valores são tabelados, de acordo com os meses do ano; T máx = temperatura máxima do dia, em ${ }^{\circ} \mathrm{C}$; $\mathrm{T}$ min = temperatura mínima do dia, em ${ }^{\circ} \mathrm{C}$; $\mathrm{T}$ = temperatura média do dia, $\mathrm{em}^{\circ} \mathrm{C}$.

\section{RESULTADOS E DISCUSSÃO}

\section{Sondagem na área das valas de infiltração}

Os resultados mostraram que todos os furos de sondagem que estão dentro das valas de infiltração (Figura 4 A, B, C e D), e portanto com solo classificado como arenoso, contém água nos $30 \mathrm{~cm}$ superficiais, enquanto o furo de sondagem que está fora do sistema (Figura $4 \mathrm{E}$ ), onde o solo tem uma classificação de solo argiloso devido a sua impermeabilidade , não apresentou água superficial. Mostrando que o sistema, já não está atendendo para o que foi projetado.

De acordo com a Figura 4, observa-se o surgimento de água nos furos efetuados sobre as valas de infiltração do sistema de tratamento de esgoto doméstico, evidenciando a saturação do sistema água. 0 sistema de tratamento de efluentes domésticos do campus Recife, IFPE, tem sua infiltração reduzida, como foi observado, provavelmente causando a formação de uma camada seladora na fossa séptica provocada pelo acúmulo de sólidos suspensos e pela atividade microbiológica, movida pela redução da infiltração 
segundo Bedbabis et al. (2014). O jardim séptico poderá ser implantado ao sistema de tratamento de esgotos composto por fossa séptica e vala de infiltração, para diminuição da saturação do solo (BEDBABIS et al., 2014).

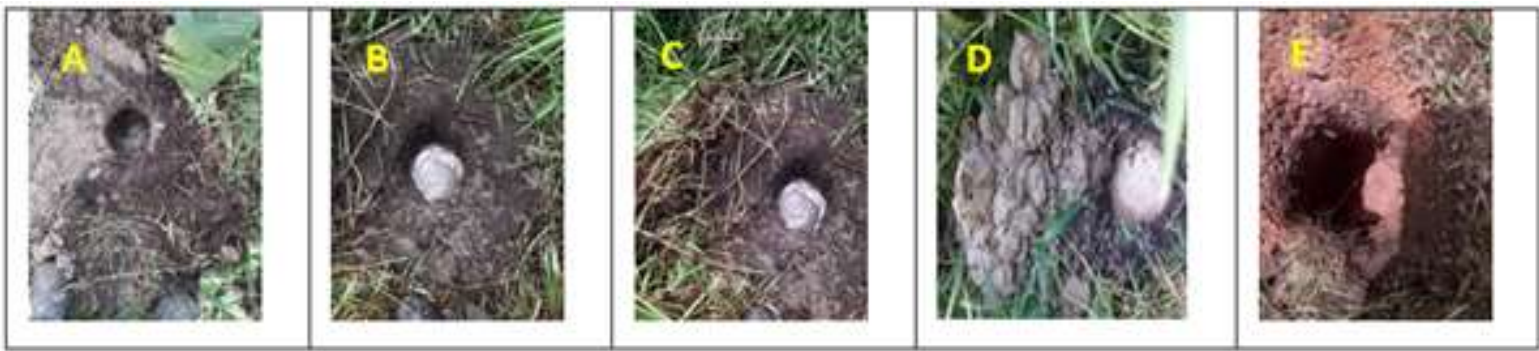

Figura 4: Avaliação das valas de infiltração do sistema de tratamento de esgoto.

\section{Dimensionamento das valas de infiltração}

Para a década de 1980 período da instalação do sistema de valas de infiltração, considerou-se uma população de 4.000 estudantes/dia, uma contribuição per capita, C, de 50 L/hab. dia e uma taxa de absorção do solo de $90 \mathrm{~L} / \mathrm{m}^{2}$.dia para o projeto, o resultado foi uma área para absorção de $2.222 \mathrm{~m}^{2}$. Esse sistema atendeu a sua finalidade projetada de 20 anos, já que o sistema possui 36 valas de infiltração estas construídas em aproximadamente $2.300 \mathrm{~m}^{2}$ de área.

O campus Recife IFPE sofreu uma expansão durante os últimos 10 anos, passando de uma população de 4 mil alunos por dia para quase 7 mil alunos por dia no ano de 2019. Para o atendimento a esta demanda a área de absorção, utilizando os mesmos dados de contribuição per capita C, de 50 L/hab.dia e taxa de absorção do solo de $90 \mathrm{~L} / \mathrm{m}^{2}$.dia, seria necessária uma área de $3.888 \mathrm{~m} 2$, portanto temos um acréscimo de $1.666 \mathrm{~m}^{2}$ de área em relação ao projeto inicial.

\section{Evapotranspiração do Sistema Wetland}

Usando a equação de Hargreaves et al., com temperatura máxima de $28.95^{\circ} \mathrm{C}$; temperatura mínima, $22.70{ }^{\circ} \mathrm{C}$, radiação extraterrestre, $5,34 \mathrm{kWh} / \mathrm{m}^{2}$.dia, obtém-se o valor de 1,34 mm.d para a evapotranspiração de referência (Etoto. De acordo com Pereira et al. (1997), citado por Galbiati (2009), "a Eto é definida como a taxa de evapotranspiração de uma cultura hipotética, com uma altura de 0,12 $\mathrm{m}$, resistência aerodinâmica da superfície de $69 \mathrm{~s} \cdot \mathrm{m}^{-1}$ e albedo de 0,23, sem falta de água". "A evapotranspiração de cultura (ETc) é a evapotranspiração de uma cultura, nos seus diferentes estágios de desenvolvimento". Logo, a razão entre a evapotranspiração de cultura e a evapotranspiração de referência é: k c=ETO/ET, definido como coeficiente da cultura (kc) e de acordo com os autores "quanto maior o coeficiente de uma cultura, maior sua evapotranspiração" (PEREIRA et al., 1997).

A estimativa da taxa de evapotranspiração em jardins sépticos é importante, pois a dinâmica da população das plantas ornamentais, tais como variação de biomassa e produtividade primária também ocorrem em regiões de clima tropical e subtropical. Segundo Esteves (2011), "a dinâmica populacional em regiões de clima tropical e subtropical são afetadas pela precipitação pluviométrica e oscilação do nível de água" 


\section{Proposta do jardim Séptico}

O projeto proposto é uma adaptação ao sistema proposto por Galbiati (2009), os chamados "jardins de águas servidas" ou jardins sépticos wetlands construídos estes são sistemas projetados para diminuir o volume de efluente. $O$ efluente primeiro entra em um tanque, de onde é bombeado para dentro do leito de pedras, onde crescem plantas pela autora, onde o efluente da fossa séptica vai para a vala de infiltração onde plantas ornamentais serão plantadas, e devido a evapotranspiração e raízes das mesmas, o fluxo subsuperficial será tratado e o efluente tratado de forma primária passando então para uma lagoa de estabilização que faz parte do sistema.

No recobrimento das valas foram indicadas plantas que servem tanto para evapotranspiração quanto para remoção de nutrientes auxiliando o tratamento do efluente proveniente da vala de infiltração. Conforme Konnerup (2009) plantas ornamentais como a Helicônia e Canna, são usadas em tratamento de esgoto sem correr o risco de sintomas de toxicidade ou deficiência de nutrientes. Segundo Marrenco et al. (2005), os fatores relacionados aos aspectos fisiológicos das plantas associados a transpiração que as torna ideais ao tratamento.

A Canna e a Helicônia (Figura 5), serão utilizadas no jardim séptico, devido as suas características de crescimento e sombreamento. Segundo Konnerup (2009) a taxa de evapotranspiração entre as duas espécies difere, onde a Canna devido a seu desenvolvimento e crescimento mais rápido e vigoroso tem uma alta taxa de ET em relação a Helicônia que tem um crescimento mais lento e ainda, quando há um aumento no volume de esgoto doméstico, o crescimento da Canna é maior, no entanto a Helicônia é uma espécie economicamente mais valiosa.

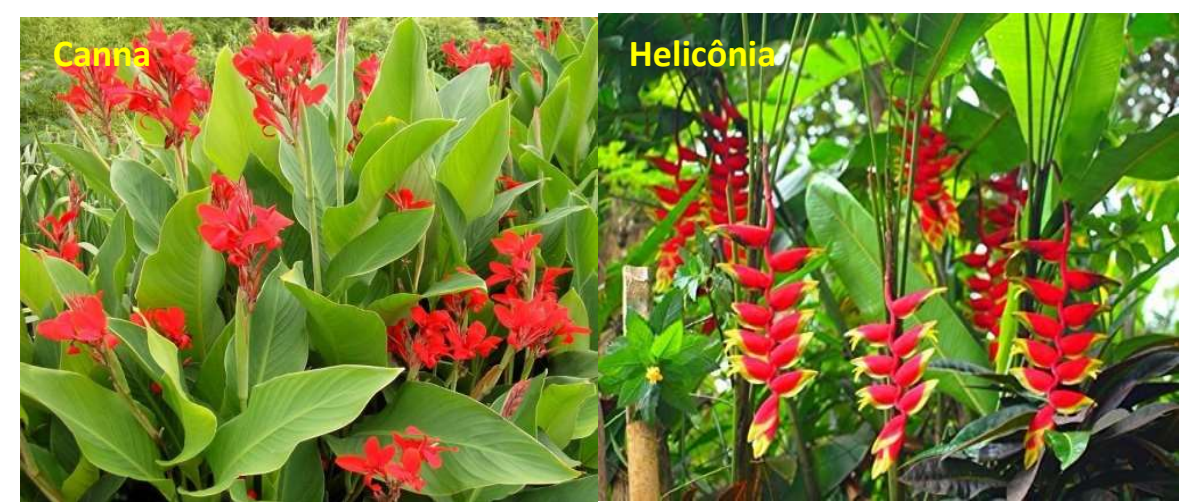

Figura 5: Plantas Ornamentais para o jardim séptico. Fonte: Konnerup (2009).

\section{Construção de Jardins Sépticos}

As Helicônias como as Cannas serão plantadas em uma distância de um metro de cada pé para outro. Cada módulo terá 252 pés das espécies, totalizando 1008 de cada espécie no jardim todo. Na figura 6 mostra uma visão superior do jardim e a figura 7 uma perspectiva. 


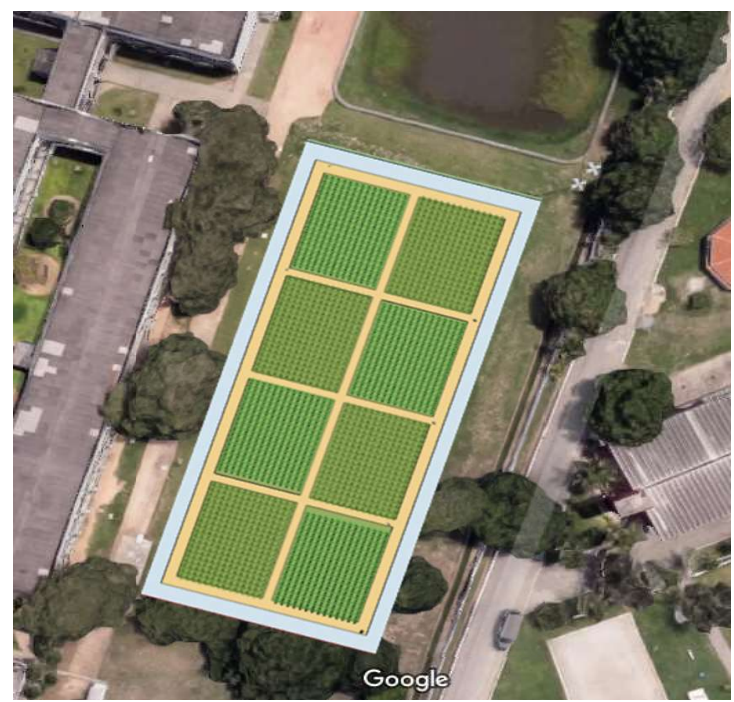

Figura 6: Vista superior do jardim.

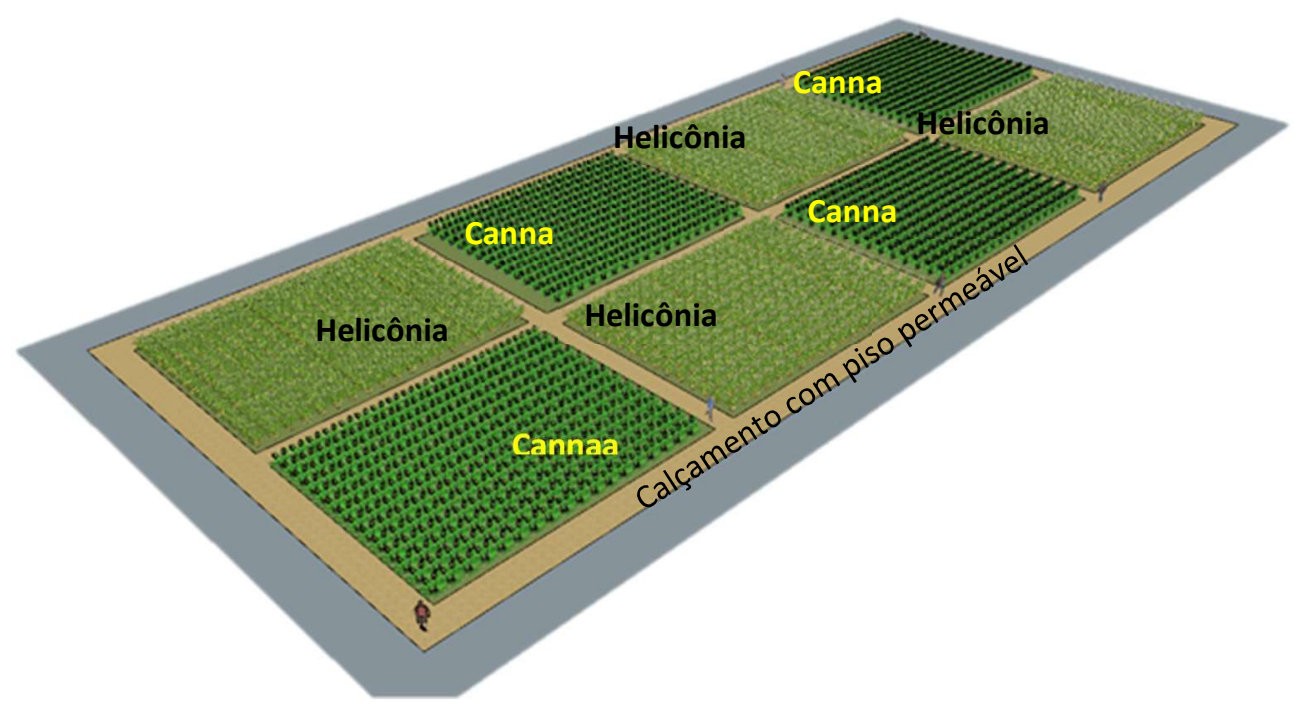

Figura 7: Perspectiva do jardim.

\section{CONCLUSÕES}

Destarte, o projeto propõe a implantação de um 'jardim séptico', que servirá de jardim contemplativo e estético e de tratamento de esgotos domésticos, aproveitando uma área de aproximadamente $2000 \mathrm{~m}^{2}$, a proposta apresenta viabilidade técnica e econômica, demonstrando eficiência na remoção nutrientes e excesso de umidade pela alta taxa de evapotranspiração das plantas sendo uma alternativa sustentável, de boa durabilidade, de baixos custos de implantação e manutenção.

O projeto traz vantagens socioeconômicas no que diz respeito à produção de flores, possibilitando o consumo ou comercialização, além de agregar valores visuais paisagísticos ao local além da preservação do meio ambiente. Espera-se que este estudo sirva de referência para implantação de novos sistemas de 'jardins sépticos' como auxiliar de tratamento de esgoto doméstico, utilizando não somente as espécies ornamentais Canna e a Heliconnia, como também outras espécies de plantas ornamentais, que possam melhorar o sistema de tratamento doméstico e ao mesmo tempo tenham um impacto visual e ambiental positivo. 


\section{REFERÊNCIAS}

ABNT. Associação Brasileira de Normas Técnicas. NBR 13969. Tanques sépticos: Unidades de tratamento complementar e disposição final dos efluentes líquidos: Projeto, construção e operação. Rio de Janeiro: ABNT, 1997.

ABNT. Associação Brasileira de Normas Técnicas. NBR 12209. Elaboração de projetos hidráulico-sanitários de estações de tratamento de esgotos sanitários. Rio de Janeiro: ABNT, 2011.

ALMEIDA, R. A.; POSCH, L. S.; PEREIRA, C. A.; GODINHO, L. F. C.; OLIVEIRA, H. J. K.. Tratamento de esgoto com plantas: sistema zona de raízes. In: Prêmio CREA-Goiás de Meio Ambiente 2004: compêndio dos trabalhos premiados. Goiania, 2005.

BEDBABIS, S.; ROUINA, B. B.; BOUKHRIS, M.; FERRARA,G. Effect of irrigation with treated wastewater on soil chemical properties and infiltration rate. Journal of Environmental Management, v.133, p.49-50, 2014.

BORIN, M.; MILANI, M.; SALVATO, M.; TOSCANO, A.. Evaluation of Phragmites australis (cav.) trin. Evapotranspiration in northern and southern italy. Ecol. Eng. v.37, p.721-728, 2011.

BRIX, H.. Functions of macrophytes in constructed wetlands. Water Sci. Technol., v.4, p.71-78, 1994.

CHANG, J.-H.. Climate and Agriculture. In: Ecological Survey. Chicago: Aldine, 1968. p.304.

CRUZ, L. M.; TONETTI, A. L.; CORAUCCI FILHO, B.; TONON, D.; STEFANUTTI, R.. Remoção da Matéria Orgânica de Efluente Doméstico por Reator Anaeróbio Preenchido com Coco Verde. Revista SABESP DAE, 2010.

ESTEVES, F. A.. Fundamentos de limnologia. 3 ed. Rio de Janeiro: Interciência, 2011.

GALBIATI, A. F.. Tratamento domiciliar de águas negras através de tanque de evapotranspiração. Dissertação (Mestrado em Ciências Exatas e Tecnologia) - Universidade Federal de Mato Grosso do Sul, Campo Grande, 2009.

HEADLEY, T. R.; DAVISON, L.; HUETT, D. O.; MULLER, R.. Evapotranspiration from subsurface horizontal flow wetlands planted with Phragmites australis in sub-tropical Australia. Water Research, v.46, p.345-354, 2012.

KONNERUP, D.; KOOTTATEPB, T.; BRIXA, H.. Treatment of domestic wastewater in tropical, subsurface flow constructed wetlands planted with Canna and Heliconia. Ecological Engineering, n.35, p.248-257, 2009.

MITSCH, W. J.; GOSSELINK, J. G.. Wetlands. 4 ed. New York: John Wiley \& Sons Inc., 2007.

PEREIRA, R. M.. Avaliação da utilização de sistemas de alagados construídos como sistema de tratamento terciário de efluentes para a geração de biomassa da cultura de taboa (Typha sp). Tese (Doutorado em Ciências Agrônomas) - Universidade Estadual Paulista, 2013.

PEREIRA, A. R.; NOVA, N. A. V.; SEDIYAMA, G. C.. Evapo(transpi)ração. Piracicaba: FEALQ, 1997.

SANDOVAL, L.; ZAMORA-CASTRO, S.; VIDAL-ÁLVAREZ, M.; MARÍN-MUÑIZ, J.. Role of Wetland Plants and Use of Ornamental Flowering Plants in Constructed Wetlands for Wastewater Treatment: A Review. Applied Sciences. v.9, n.4, p.685., 2019. DOI: http://doi.org/10.3390/app9040685

SHELEF, O.; GROSS, A.; RACHMILEVITCH, S.. Review Role of Plants in a Constructed Wetland: Current and New Perspectives. Water, v.5, p.405-419, 2013. DOI: http://doi.org/10.3390/w5020405

SIEVERS, D. M.. Design of submerged flow wetlands for individual homes and small wastewater flows. Columbia: University of Missouri, 1993.

SOLANO, M. L.; SORIANO, P.; CIRIA, M. P.. Constructed wetlands as a sustainable solution for wastewater treatment in small villages. Biosystems Engineering, v.1, n.87, p.109118, 2004.

TUCCI, C. E. M.. Hidrologia: ciência e aplicação. Porto Alegre: UFRGS-ABRH, 1997.

TCHOBANOGLOUS, G.. Constructed wetlands: natural treatment system. In: TCHOBANOGLOUS, G.. Wastewater engineering: treatment, disposal, and reuse. 3 ed. Toronto: Metcalf. \& Eddy, Mc Graw-Hill, 1991. p.992-1002.

A CBPC - Companhia Brasileira de Produção Científica (CNPJ: 11.221.422/0001-03) detém os direitos materiais desta publicação. Os direitos referem-se à publicação do trabalho em qualquer parte do mundo, incluindo os direitos às renovações, expansões e disseminações da contribuição, bem como outros direitos subsidiários. Todos os trabalhos publicados eletronicamente poderão posteriormente ser publicados em coletâneas impressas sob coordenação da Sustenere Publishing, da Companhia Brasileira de Produção Científica e seus parceiros autorizados. Os (as) autores (as) preservam os direitos autorais, mas não têm permissão para a publicação da contribuição em outro meio, impresso ou digital, em português ou em tradução. 